\title{
Penguatan Community Development Petani Nanas Desa Palaan melalui Digital Marketing
}

\author{
Lian Agustina Setiyaningsih ${ }^{1}$, Muhammad Hanif Fahmi \\ ${ }^{1}$ Departemen IImu Komunikasi, Fakultas IImu Sosial dan IImu Politik, Universitas Merdeka Malang, Jl. Terusan Raya Dieng \\ No.62-64 Malang, 65146, Indonesia \\ ${ }^{2}$ Departemen Sistem Informasi, Fakultas Sains dan Teknologi Universitas Islam Raden Rahmat Malang, Jl. Raya Mojosari \\ No.2, Malang, 65163, Indonesia
}

\section{ARTICLE INFO:}

Received: 2020-04-17

Revised: 2020-05-21

Accepted: $2020-06-15$

\section{Keywords:}

Community development;

Digital marketing;

Pineapple farmers

\section{ABSTRACT}

Palaan Village, Kecamatan Ngajum, Kabupaten Malang, has a village superior product embryo, namely premium quality pineapple. At the same time it has an educational destination for pineapple villages. Pineapple farmers in Palaan have problems that often suffer losses when selling their harvests through middlemen. The problem of partners is divided into two: 1) conventional harvest sales, and 2) financial management is not yet able. Then the activities that can be carried out to answer these problems through digital marketing training by creating an online store for crop marketing. As well as providing knowledge and skills of a simple financial system application for managing crop yields. The results of this activity in the form of an online shop owned by a group of farmers managed by Karang Taruna and Bumdes. And a simple financial system application for pineapple farmers in Palaan Village. The use of this application, the marketing target is more extended to all regions in Indonesia

(C) 2020 Published by University of Merdeka Malang This is an open access article distributed under the CC BY-SA 4.0 license (https://creativecommons.org/licenses/by-sa/4.0/)

How to cite: Setiyaningsih, L. A., \& Fahmi, M. H. (2020). Penguatan Community Development Petani Nanas Desa Palaan melalui Digital Marketing. Abdimas: Jurnal Pengabdian Masyarakat Universitas Merdeka Malang, 5(2), 145151. https://doi.org/10.26905/abdimas.v5i2.4361

\section{PENDAHULUAN}

Di Desa Palaan telah dikembangkan pemanfaatan lahan pekarangan rumah untuk ditanami tanaman buah nanas. Selain dapat mempercantik halaman rumah, dengan menanam buah nanas akan menambah pendapatan dan mengurangi pengeluaran rumah tangga untuk memenuhi kebutuhan vitamin dari buah yang dibutuhkan tubuh. Nanas di Desa Palaan yang sebagian besar tumbuh dan berkembang di Dusun Sukoyuwono ini telah berlangsung bertahun-tahun. Memiliki keunikan khusus daripada nanas pada umumnya. Ketika sudah tua layak panen nanas ini beratnya hingga 3-5 Kg/biji. Meskipun Jumbo, rasanya tetap 
ABDIMAS: Jurnal Pengabdian Masyarakat Universitas Merdeka Malang

Volume 5, No 2, Juli 2020: 145-151

manis. Daunnya pun lebar dan panjang lagi tidak berduri. Sehingga kita tidak perlu khawatir menyentuh karena takut tertusuk duri sebagaimana tanaman nanas pada umunya.

Desa Palaan terletak di Kabupaten Malang yang memiliki lahan tegal atau kebun seluas 8,60 Ha. Desa Palaan terdiri dari 10 Rukun Warga (RW) yang tergabung di dalam 2 Dusun Palaan-Krajan dan Dusun Sukoyuwono. Dusun ini menjadi lokasi lahan pembudidayaan nanas. Sebelumnya, pembudidayaan nanas hanya ada di pekarangan warga, namun seiring dengan pendampingan terhadap warga setempat yang terbiasa menanam nanas maka terciptalah komunitas petani nanas dengan satu lahan terpadu di Dusun Sukoyuwono. Tempat tersebut juga telah didesain menjadi destinasi wisata edukasi yang bertujuan mengembangkan ekonomi lokal penduduk Desa Palaan. Dengan teknik budidaya yang telah dilakukan masyarakat yaitu pengaturan waktu tanam, rata-rata dalam satu kali panen Desa Palaan menghasilkan nanas sejumlah 11,5 ton/bulan dengan masa tanam 8 bulan.

Permasalahan yang muncul setelah pasca panen adalah petani nanas belum bisa melakukan pemasaran secara mandiri dan langsung. Seluruh pemasarannya dilakukan dengan cara konvensional yang bergantung pada tengkulak. Harga jual yang rendah jika diborong oleh tengkulak sering kali menjadi kerugian besar bagi para petani nanas. Padahal jika di pasar modern maupun supermarket, harga nanas bisa dijual dengan harga tinggi karena kualitasnya yang premium. Proses perdagangan yang demikian dinilai para petani sering membuat kerugian secara ekonomi. Dengan kondisi tersebut, maka perlu diberikan pelatihan dan pendampingan bagaimana petani nanas dapat memanfaatkan metode digital marketing yang berguna untuk dapat mengelola produk komunitas, sehingga memperoleh penghasilan yang lebih layak.

Wiediawati, Pratiwi, \& Bimandra (2019), menjelaskan bahwa pelatihan digital marketing mampu membentuk kemandirian masyarakat berbasis komunitas. Begitu juga Yudaninggar (2019) menuliskan digital marketing berbasis komunitas pada pedagang Batik Sojiwan mampu meningkatkan kemampuan kemandirian kelompok tersebut. Hal serupa juga terjadi pada kelompok ibu rumah tangga di Kota Malang. Menurut Setiyaningsih (2017), peningkatan pendapatan ibu rumah tangga sebagai penyokong perekonomian keluarga dapat dicapai melalui cyber promotion dan digital marketing.

Selain menumbuhkan kemandirian, pemanfaatan digital marketing juga mampu menumbuhkan daya saing perdagangan (Ahmad et al., 2019). Dalam pelaksanaannya membutuhkan strategi guna meningkatkan nilai perdagangan dan jangkauan sebar pemasaran (Krisnawati et al., 2019; Mustika, 2019), yaitu berupa menyusun konten marketing, pesan marketing, layout yang menarik, serta target sasaran pembeli yang tepat (Baltes, 2015). Hollebeek \& Macky (2019) mengungkapkan bahwa dengan menggunakan digital marketing dapat mempererat hubungan, menumbuhkan kepercayaan, serta nilai tambah produk kepada konsumen.

Digital marketing juga harus diikuti dengan kemampuan para petani dalam mengelola keuangan mereka. Fariana et al. (2020), menjelaskan bahwa pelatihan pengelolaan keuangan dapat membantu para petani atau kelompok kewirausahaan lainnya untuk meningkatkan kinerja keuangannya. Pada dasarnya, peningkatan kemampuan manajemen menjadi dasar dalam meningkatkan nilai perdagangan petani. Seperti studi yang pernah dilakukan di California, bahwa komunitas petani dapat menghubungkan kepentingan para petani dalam mendistribusikan hasil panennya (Brodt, et al., 2006).

Garnevska, Liu, \& Shadbolt, (2011) kesuksesan perekonomian petani di Cina dimulai dari pengembangan kemampuan dan keterampilan petani berbasis komunitas. Community development menjadi dasar 


\section{Penguatan Community Development Petani Nanas Desa Palaan melalui Digital Marketing}

Lian Agustina Setiyaningsih, Muhammad Hanif Fahmi

pergerakan aktivitas petani di Cina. Suswanto, Handoko, \& Sabiq (2013) menambah model community development berbasis kearifan lokal dan berdasarkan karakteristik petani merupakan strategi pemberdayaan yang efektif. Pada akhirnya pemberdayaan berbasis komunitas dapat meningkatkan pendapatan, jejaring, serta solidaritas para petani (Ar-rozi, Kolopaking, \& Agusta, 2019).

Oleh karenanya, pelatihan digital marketing kepada petani nanas yang disokong oleh karang taruna desa setempat menjadi solusi untuk mengurai kerugian ekonomi yang mereka alami. Selain itu jawaban pelatihan dalam melakukan manajemen keuangan secara sederhana juga merupakan langkah selanjutnya untuk menguatkan keterampilan petani nanas agar lebih mandiri dalam mengelola keuangan dari hasil panen mereka.

Adapun solusi yang dapat dirumuskan untuk menyelesaikan permasalahan di masyarakat tersebut adalah memberikan pelatihan soft skill digital marketing kepada petani nanas melalui toko online dan peningkatan kapasitas dalam manajemen keuangan dan strategi pemasaran dan branding. Target luaran dari kegiatan pelatihan ini adalah membuat akun pemasaran di platform toko online dan menghasilkan aplikasi sistem keuangan sederhana bagi petani nanas sehingga transaksi dapat tercatat dan teranalisis.

\section{METODE}

Metode kegiatan ini dibagi menjadi dua tahap, yakni pengembangan akun pemasaran dan kemampuan manajemen. Pengembangan akun pemasaran memiliki tiga langkah membuat desain konten, akun toko online, dan praktik langsung. Sedangkan peningkatan kemampuan manajemen meliputi tabulasi kebutuhan, merancang dan menerapkan aplikasi keuangan serta praktik langsung. Berikut merupakan bagan metode kegiatan pendampingan petani nanas (Gambar 1).
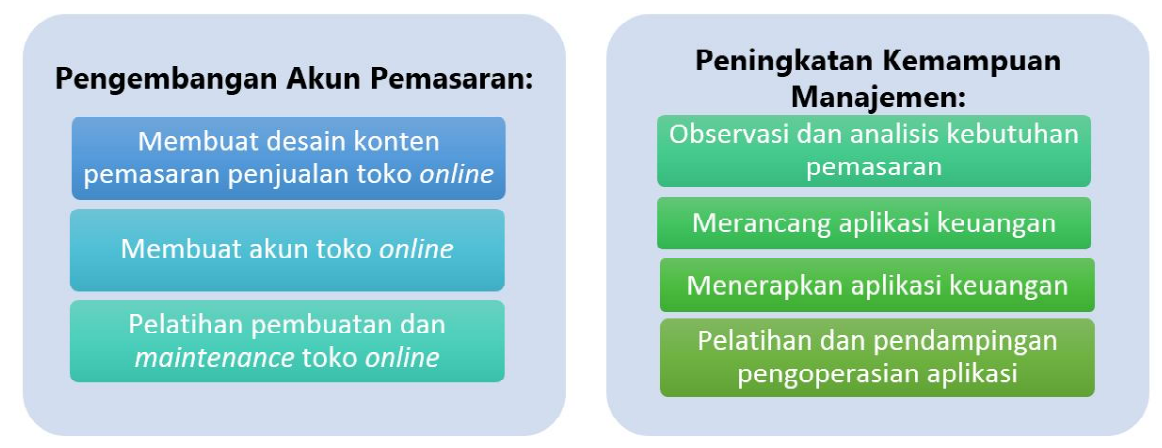

Gambar 1. Bagan metode pelaksanaan kegiatan

\section{HASIL DAN PEMBAHASAN}

Kegiatan ini melibatkan petani nanas dan karang taruna Desa Palaan. Pelibatan karang taruna memiliki tujuan untuk menopang keterampilan para petani nanas dan bekerja sama dengan BUMDes dalam penjualan hasil panen. Sebagain besar petani nanas berusia di atas 45 tahun dan berjenis kelamin perempuan. Dari hasil observasi, mereka rata-rata belum memiliki keterampilan dalam menggunakan perangkat teknologi. Sehingga karang taruna difungsikan sebagai gatekeeper dalam mengoperasikan toko online maupun aplikasi keuangan. 
ABDIMAS: Jurnal Pengabdian Masyarakat Universitas Merdeka Malang Volume 5, No 2, Juli 2020: 145-151

Hasil dari kegiatan pendampingan berbasis community development dalam mengembangkan keterampilan dan kemampuan petani nanas di Desa Palaan berkaitan dengan digital marketing adalah sebagai berikut.

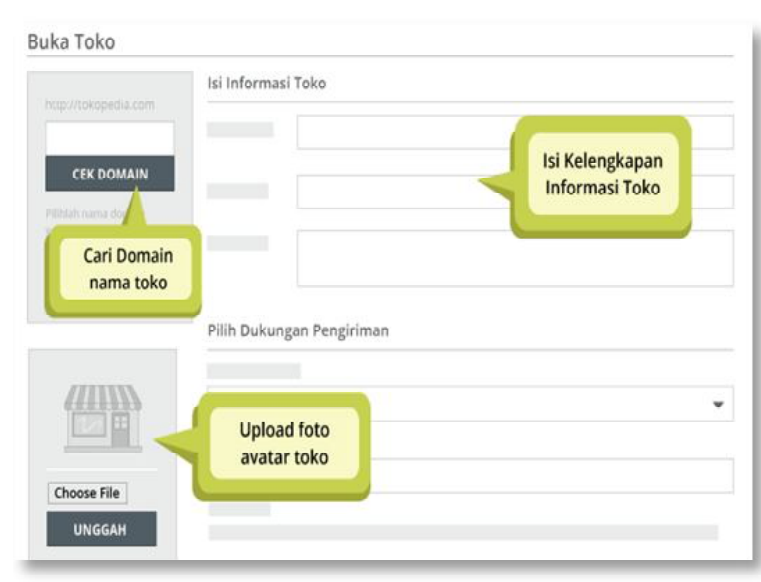

Gambar 2. Langkah membuat gerai online

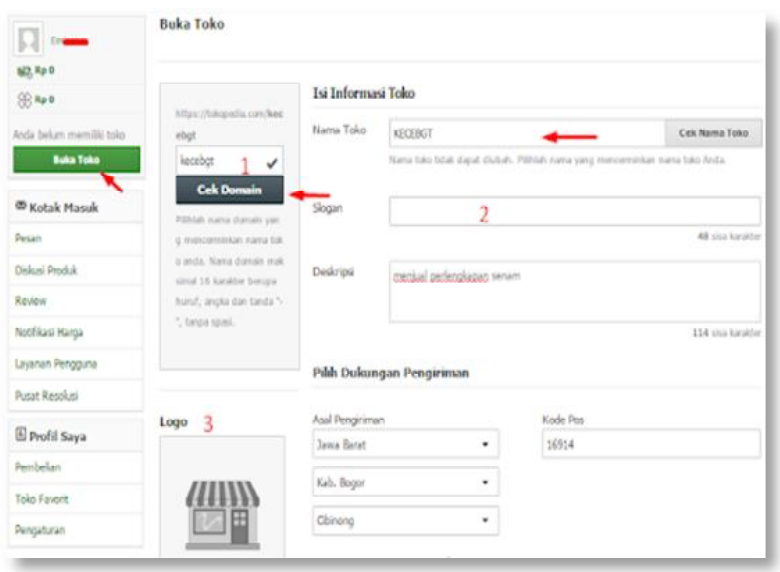

Gambar 3. Memberikan identitas toko online

Pada Gambar 2 merupakan langkah awal yang harus dilakukan adalah mendaftarkan diri sebagai pelaku usaha di platform toko online. Mitra diajarkan cara membuat gerai online untuk pemasaran hasil panen secara online.

Gambar 3 merupakan cara untuk memberikan identitas pada toko online. Sedangkan Gambar 4 merupakan cara untuk membuka toko dan siap untuk mendisplay produk.

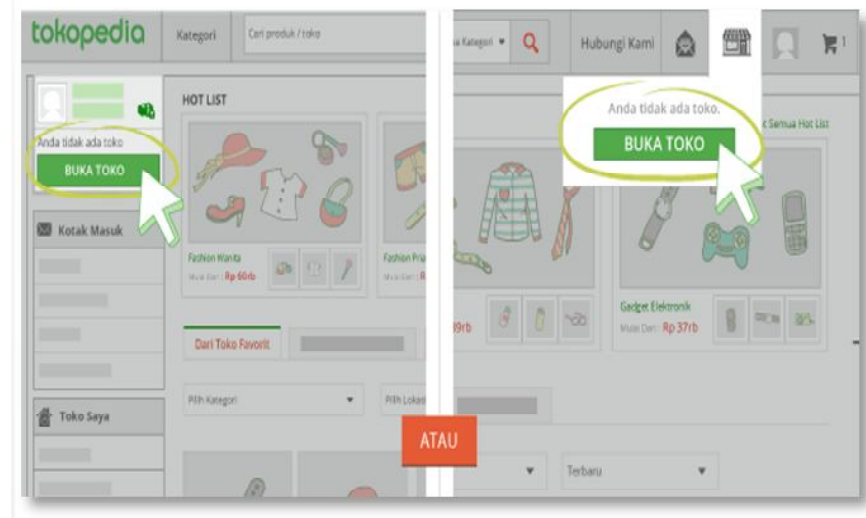

Gambar 4. Mengoperasionalkan toko online

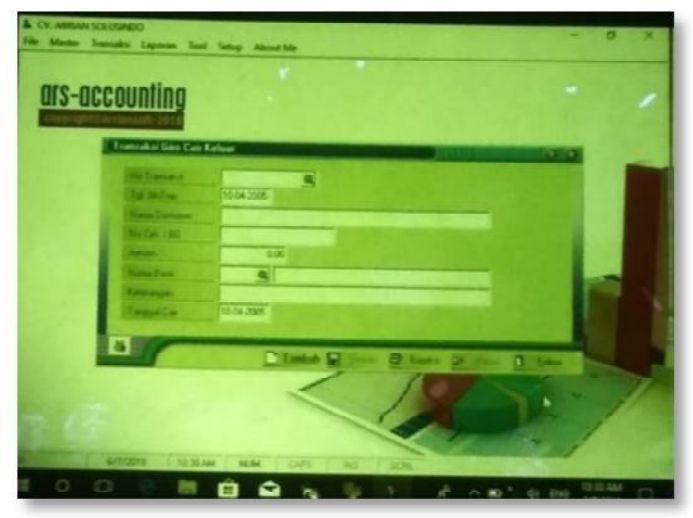

Gambar 5. Login aplikasi keuangan online

Gambar 5 menunjukkan langkah awal untuk masuk dalam akun aplikasi keuangan online. Dan saat mitra akan membuat lapiran keuangan akan bertemu dengan halaman master rekening. Fungsinya adalah merupakan halaman yang berisikan menu pengelolaan keuangan yang ada pada Gambar 6. 




Gambar 6. Menu Master Rekening

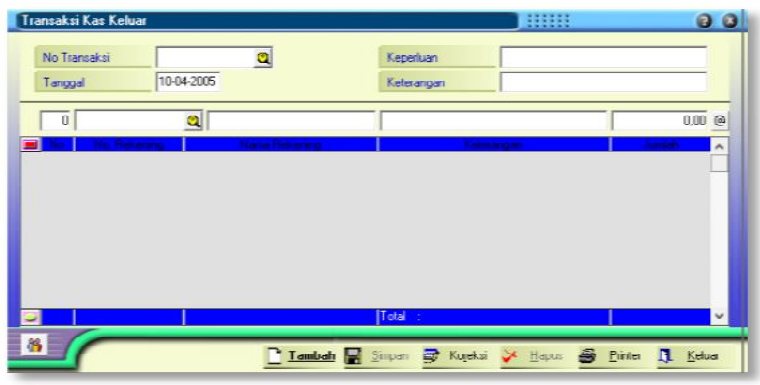

Gambar 7. Menu Kas Keluar

Dalam pelatihan mengoperasikan aplikasi keuangan, mitra juga diajak untuk berlatih dalam membuat kas keluar dan kas masuk. Tujuannya adalah agar mitra dapat mencatat secara rinci pengeluaran dan pemasukan dari hasil panen nasasnya.

Untuk menu kas masuk dapat dilihat pada Gambar 8. Dimana fungsinya mencatat hasil penjualan dari hasil panen nanas.

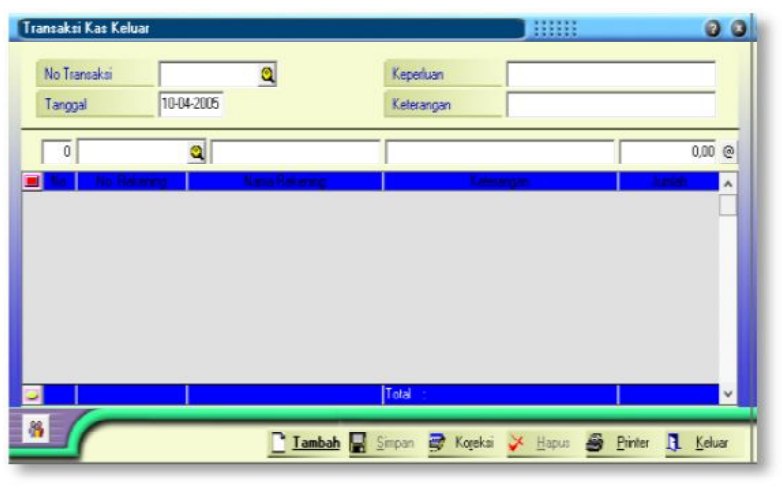

Gambar 8. Menu Kas Masuk



Gambar 9. Pelatihan Digital Marketing

Menu dalam aplikasi keuangan sederhana ini telah disesuaikan dengan kebutuhan petani nanas. Menu yang ada berkaitan dengan kas masuk dan keluar, pengelolaan penjualan, display produk (Gambar 8).

Community development diartikan sebagai kekuatan dalam pemberdayaan terhadap petani nanas yang terletak pada pengembangan keterampilan dan pengetahuan yang melibatkan komunitas. Seluruh kegitan dilakukan dan dikontrol oleh komunitas tersebut, dalam hal ini adalah petani nanas.

Selama ini penjualan dari hasil panen nanas diborong oleh tengkulak dengan harga yang cukup murah. Untuk memotong mata rantai penjulan yang rumit, maka toko online menjadi solusinya. Petani nanas mendapatkan untung sedikit dari penjualan kepada tengkulak. Dalam rangka meneruskan agenda membangun destinasi wisata edukasi di Desa Palaan, petani juga bisa langsung menjual secara langsung kepada pengunjung. Selain itu penjualan mereka juga bisa menjangkau seluruh Indonesia. 
ABDIMAS: Jurnal Pengabdian Masyarakat Universitas Merdeka Malang

Volume 5, No 2, Juli 2020: 145-151

\section{SIMPULAN DAN SARAN}

\section{Simpulan}

Kegiatan pelatihan digital marketing berbasis community development pada petani nanas ini merupakan rangkaian kegiatan dalam membangun destinasi wisata edukasi di Desa Palaan. Tujuan utama dari kegiatan ini adalah memberikan pengetahuan dan keterampilan kepada mitra. Pelatihan yang diberikan antara lain membuat toko online dan aplikasi keuangan sederhana. Sedangkan produk yang dihasilkan adalah toko online petani nanas dan aplikasi keuangan sederhana. Community development pada petani nanas melibatkan karang taruna dan BUMDes untuk menopang siklus keberhasilan peningkatan perekonomian desa Palaan. Petani dapat memotong mata rantai penjualan yang panjang melalui toko online dan target pemasarannya menjadi lebih luas hingga jangkauannya ke seluruh daerah di Indonesia. Sedangkan aplikasi sistem informasi keuangan secara sederhana merupakan langkah selanjutnya untuk mengorganisir keuangan pasca panen.

\section{Saran}

Dalam rangka keberlanjutan pelaksanaan kegiatan, sebaiknya perlu dilakukan evaluasi dan pendampingan secara berkesinambungan oleh karang taruna dan BUMDes kepada petani nanas, sehingga kegiatan ini bisa berlangsung secara terus menerus. Hendaknya dapat menjaga kerjasama antar petani agar tidak terjadi monopoli penjualan dan dominasi dalam pengelolaan hasil panen. Bagi pengabdi selanjutnya, perlu dilakukan program pelatihan pengolahan produk nanas yang lebih kreatif dan inovatif, sehingga dapat memberikan daya tarik bagi toko online mereka.

\section{DAFTAR PUSTAKA}

Ahmad, M., Perdana, F. R., Utami, K. S., \& Harjanta, S. L. (2019). Pengolahan kopi bubuk dan pemasaran berbasis digital marketing dalam meningkatkan daya saing hilirisasi kopi di Kawasan Lereng Menoreh. Adi Widya: Jurnal Pengabdian Masyarakat, 3(1), 38-46.

https://doi.org/10.33061/awpm.v3i1.3074

Ar-Rozi, A. M., Kolopaking, L. M., \& Agusta, I. (2019). The role of Swadesa Marketing Institutions in increasing farmer's income. Sodality: Jurnal Sosiologi Pedesaan, 7(1), 1-9. https://doi.org/10.22500/sodality.v7i1.21269

Baltes, L. P. (2015). Content marketing-the fundamental tool of digital marketing. Bulletin of the Transilvania University of Brasov. Economic Sciences. Series V, 8(2), 111.

Brodt, S., Feenstra, G., Kozloff, R., Klonsky, K., \& Tourte, L. (2006). Farmer-community connections and the future of ecological agriculture in California. Agriculture and human values, 23(1), 75-88. https://doi.org/10.1007/s10460-004-5870-y

Garnevska, E., Liu, G., \& Shadbolt, N. M. (2011). Factors for successful development of farmer cooperatives in Northwest China. International Food and Agribusiness Management Review, 14(10302016-82904), 69-84.

Hollebeek, L. D., \& Macky, K. (2019). Digital content marketing's role in fostering consumer engagement, trust, and value: Framework, fundamental propositions, and implications. Journal of Interactive Marketing, 45, 27-41. https://doi.org/10.1016/j.intmar.2018.07.003 


\section{Penguatan Community Development Petani Nanas Desa Palaan melalui Digital Marketing}

Lian Agustina Setiyaningsih, Muhammad Hanif Fahmi

Krisnawati, I., Ubaidi, I. A., Rais, H., \& Batu, R. L. (2019). Strategi digital marketing dalam perdagangan hasil tani untuk meningkatkan pendapatan Kabupaten Karawang. Jurnal Ilmiah Ekonomi Global Masa Kini, 10(2), 70-75.

Fariana, R., Fauziyah, Purwanto, T., \& Adi, B. (2020). Pelatihan pembukuan sederhana untuk meningkatkan kinerja keuangan pelaku usaha di Desa Kebontunggul Kecamatan Gondang Kabupaten Mojokerto. Ekobis Abdimas: Jurnal Pengabdian Masyarakat, 1(1), 37-44.

https://doi.org/10.36456/ekobisabdimas.1.1.37-44.2339

Mustika, (2019). Penerapan teknologi digital marketing untuk meningkatkan strategi pemasaran Snack Tiwul. JSAI (Journal Scientific and Applied Informatics), 2(2), 165-171.

https://doi.org/10.36085/jsai.v2i2.352

Setiyaningsih, L. A. (2017). Pelatihan handycraft talenan vintage dan cyber promotion untuk ibu rumah tangga berpenghasilan rendah Kelurahan Kasin Kota Malang. Abdimas: Jurnal Pengabdian Masyarakat Universitas Merdeka Malang, 1(1), 44-46. https://doi.org/10.26905/abdimas.v1i1.1174

Suswanto, B., Handoko, W., \& Sabiq, A. (2013). Model community development sebagai strategi pemberdayaan berbasis kearifan lokal. Jurnal Review Politik, 3(2), 298-312.

Wiediawati, A. M., Pratiwi, A. A., \& Bimandra, G. (2019). Pelatihan digital marketing strategy untuk mencapai kemandirian masyarakat. Dinamisia: Jurnal Pengabdian Kepada Masyarakat, 3(1), 147-157. https://doi.org/10.31849/dinamisia.v3i1.2676

Yudaninggar, K. (2019). Pelatihan digital marketing dalam rangka peningkatan pemasaran Kelompok Batik Sojiwan. Prosiding. Seminar Hasil Pengabdian Masyarakat. Universitas Amikom Yogyakarta. 